\title{
Alireza Hojabri-Nobari, Alireza Khosrozadeh, Seyed Mehdi Mousavi Kouhpar, Hamed Vahdatinasab. Trade and Cultural Contacts between Northern and Southern Persian Gulf during Parthians and Sasanians: A Study based on Pottery from Qeshm Island
}

\section{Rémy Boucharlat}

\section{(2) OpenEdition}

Édition électronique

URL : http://journals.openedition.org/abstractairanica/41807

DOI : 10.4000/abstractairanica.41807

ISSN : 1961-960X

Éditeur :

CNRS (UMR 7528 Mondes iraniens et indiens), Éditions de l'IFRI

Référence électronique

Rémy Boucharlat, « Alireza Hojabri-Nobari, Alireza Khosrozadeh, Seyed Mehdi Mousavi Kouhpar, Hamed Vahdatinasab. Trade and Cultural Contacts between Northern and Southern Persian Gulf during Parthians and Sasanians: A Study based on Pottery from Qeshm Island », Abstracta Iranica [En ligne], Volume 34-35-36 | 2017, document 21, mis en ligne le 30 décembre 2016, consulté le 03 octobre 2020. URL : http://journals.openedition.org/abstractairanica/41807 ; DOI : https://doi.org/10.4000/ abstractairanica. 41807

Ce document a été généré automatiquement le 3 octobre 2020.

Tous droits réservés 


\section{Alireza Hojabri-Nobari, Alireza Khosrozadeh, Seyed Mehdi Mousavi Kouhpar, Hamed Vahdatinasab. Trade and Cultural Contacts between Northern and Southern Persian Gulf during Parthians and Sasanians: A Study based on Pottery from Qeshm Island}

Rémy Boucharlat

\section{RÉFÉRENCE}

Alireza Hojabri-Nobari, Alireza Khosrozadeh, Seyed Mehdi Mousavi Kouhpar, Hamed Vahdatinasab. " Trade and Cultural Contacts between Northern and Southern Persian Gulf during Parthians and Sasanians: A Study based on Pottery from Qeshm Island ». International Journal of Humanities, 18, 2, 2011, p. 89-113.

Ces premiers résultats d'une prospection archéologique conduite en 2006 sont les bienvenus tant la côte iranienne du golfe Persique est encore trop méconnue. Le corpus céramique des périodes parthe (à partir $\mathrm{du} \mathrm{I}^{\mathrm{er}} \mathrm{s}$. de n.è.) et sassanide est très proche de celui de plusieurs sites fouillés sur l'autre rive du golfe (ed-Dur, Kush et Mleiha), ainsi que Sohar sur l'océan Indien. Ces catégories ont été reconnues également, mais par des prospections seulement, dans le Kermān méridional et le Balūčestān. Il y a bien des productions régionales, et non pas à l'échelle des empires, ici l'Iran méridional, comme 
l'avait bien défini en 1983, E. Haerinck récemment disparu. À cette époque la rive arabe du golfe Persique n'était pas connue ; il faut maintenant inclure cette côte dans une même aire culturelle, les rives du golfe Persique.

\section{AUTEURS}

\section{RÉMY BOUCHARLAT}

CNRS, Paris 